\title{
Abnormal cardiotocographic findings and perinatal outcome: a prospective study
}

\author{
Maitrayee Sen $^{1}$, Sunita Samal ${ }^{1 *}$, Sajal Datta ${ }^{2}$, Melvin George ${ }^{3}$
}

\begin{abstract}
${ }^{1}$ Department of Obstetrics and Gynecology, S. R. M. Medical College Hospital and Research Center, Kattankulathur, Chennai, India

${ }^{2}$ Department of Obstetrics and Gynecology, Vivekananda Institute of Medical Sciences, Ramakrishna Mission Seva Pratisthan, Kolkata, West Bengal, India

${ }^{3}$ Department of Clinical Pharmacology, S. R. M. Medical College Hospital and Research Center, Kattankulathur, Chennai, India
\end{abstract}

Received: 17 August 2019

Accepted: 30 September 2019

\section{*Correspondence:}

Dr. Sunita Samal,

E-mail: sunitasonesh@gmail.com

Copyright: (c) the author(s), publisher and licensee Medip Academy. This is an open-access article distributed under the terms of the Creative Commons Attribution Non-Commercial License, which permits unrestricted non-commercial use, distribution, and reproduction in any medium, provided the original work is properly cited.

\section{ABSTRACT}

Background: CTG as an intrapartum fetal surveillance can be judged appropriately taking the abnormal features of CTG individually into account for decision making of early delivery to reduce the fetal and neonatal morbidity. Objectives of this study were to identify the fetuses at risk of developing hypoxia as evidenced by abnormal FHR pattern seen by CTG and to correlate the abnormal features with perinatal outcome and find out the most specific feature among all abnormal features of CTG in detecting the adverse perinatal outcome.

Methods: This was an observational study where total of 249 uncomplicated pregnant patients in active labor were selected randomly and CTG were done for them. Progress of labor was recorded in partogram. Only pathological CTGs were considered for early decision of delivery by LSCS. After delivery Apgar score 1 min, 5 min, baby weight, colour of liquor, NICU admission and no of days of admission in NICU were recorded.

Results: For liquor colour, variability and absence of acceleration were good screening heart rate features and baseline was considered the most specific feature. For all babies with poor Apgar score at 1 min, abnormal baseline was the most specific feature. For NICU admission, the abnormal baseline the most specific feature. Acceleration was found to be the most sensitive heart rate feature among all other heart rate features. Liquor colour had better sensitivity for detecting poor Apgar score at $1 \mathrm{~min}$ and $5 \mathrm{~min}$. There was increase rate of cesarean section and operative vaginal delivery.

Conclusions: Abnormal intrapartum CTG features of an uncomplicated laboring mother $>37$ weeks can detect fetuses at distress with different specificities and sensitivities when considered individually and can reduce the perinatal morbidity.

Keywords: Abnormal heart rate features, Cardiotocography, Perinatal outcome

\section{INTRODUCTION}

Intrapartum "Non reassuring fetal status" (fetal distress) attributed to fetal hypoxia is an important cause of adverse perinatal outcome in the form of still birth, neonatal death, cerebral palsy and seizures after birth. Uterine contraction in labour put stress on placental circulation resulting in hypotension in fetal circulation. In 
addition, there is head compression which affects the vital centers in the fetal brain. The combination of hypoxemia and cerebral ischemia due to hypotension causes a marked reduction in cerebral dysfunction and brain damage. With prolonged and profound hypoxia, anaerobic metabolism within the fetus results in lactic academia which aggravates acidosis. ${ }^{1}$ The goal of intrapartum fetal surveillance is the diagnosis of fetal exposure to hypoxia and detection of fetal behavioural abnormalities at a stage where they are reversible. The current modalities of intrapartum fetal monitoring includes, assessing the colour of liquor, quantity of amniotic fluid, intermittent fetal heart rate auscultation, intrapartum cardiotocography, fetal scalp blood sampling cord blood gas estimation, fetal pulse oximetry and ST analysis of fetal ECG. ${ }^{2}$ Cardiotocography has been used as a basic noninvasive method of evaluating fetal condition during pregnancy and labour. ${ }^{3}$ A nonreassuring trace occurs in up to $50 \%$ of all recordings but only a small proportion of these fetuses are at risk of hypoxia. ${ }^{4}$ Clinical outcome of fetal distress can be assessed by Apgar score, umbilical artery PH, neonatal encephalopathy, perinatal death and cerebral palsy which have been used in isolation or in combination.

The present prospective observational study was performed to correlate perinatal outcome with abnormal fetal heart rate patterns (RCOG 2001) as evidenced by electronic fetal monitoring by cardiotocography during labour.

\section{METHODS}

This was an observational study conducted in department of obstetrics and gynecology, Vivekananda Institute of Medical Sciences, Ramakrishna Mission Seva Pratisthan, Kolkata. A total of 249 pregnant patients in labour were taken for this study and were selected randomly. All the women were at term and were in either spontaneous or induced labour. Women with preterm labour, multiple pregnancies or with any medical or surgical or obstetrical complications were excluded from study. They were followed up both by clinically and intermittent electronic fetal rate monitoring (Doppler, cardiotocography) during labour. Progress of labour, fetal heart rate monitoring were recorded in partograph. Active management if necessary was offered to those laboring women.

The RCOG 2001 grading system of fetal heart rate patterns and categorization scheme was followed in this study. Decision of cesarean section or any obstetric intervention was taken when CTG was pathological or if on duty doctor feels it was mandatory despite normal or suspicious CTG in the presence of other abnormal clinical findings. Overall outcome was assessed in terms of mode of delivery, Apgar score of the neonate at $1 \mathrm{~min}$ and $5 \mathrm{~min}$, colour of liquor, presence or absence of seizures, NICU admission, duration of hospital stays and other adverse perinatal factors during the hospital stay. These were correlated with the abnormal CTG findings. Medical records were checked for maternal demographic characteristics antenatal history and birth data. Variables reviewed were maternal age, parity. After delivery, Apgar score at $1 \mathrm{~min}$ and $5 \mathrm{~min}$, baby's sex, baby weight, colour were recorded. Apgar score $<7$ at $1 \mathrm{~min}$ was considered low. If baby was shifted to NICU, duration of NICU stay was recorded.

\section{RESULTS}

In our study sample, out of 249 cases with pathological CTG, 1 had abnormal baseline, 3 had non reassuring baseline and 245 had reassuring baseline. So, $98.39 \%$ of pathological CTG had reassuring baselines. Similarly, 7 cases had abnormal variability, 41 had non reassuring variability and 201 cases had reassuring variability. So, $80.72 \%$ of the pathological CTG had reassuring variability. Among deceleration, 173 (69.48\%) had atypical variable deceleration, $62(24.90 \%)$ had single prolonged deceleration and $14(5.62 \%)$ had late deceleration. Of 249 cases, 103 cases had acceleration and in 146 cases there were no acceleration (Table 1).

Table 1: Incidence of baseline, variability, acceleration and types of abnormal deceleration.

\begin{tabular}{|llllll|}
\hline & Baseline & Variabilty & Acceleration & \multicolumn{2}{c|}{ Deceleration } \\
\hline Abnormal & $1(0.4 \%)$ & $7(2.81 \%)$ & $146(58.63 \%)$ & SPD & $62(24.90 \%)$ \\
\hline Non-reassuring & $3(1.20 \%)$ & $41(16.47 \%)$ & & AVD & $173(69.48 \%)$ \\
\hline Reassuring & $245(98.29 \%)$ & $201(80.72 \%)$ & $103(41.37 \%)$ & LD & $14(5.62 \%)$ \\
\hline Grand total & $\mathbf{2 4 9}$ & $\mathbf{2 4 9}$ & $\mathbf{2 4 9}$ & & $\mathbf{2 4 9}$ \\
\hline
\end{tabular}

When we compared baseline heart rate with colour of liquor, only 1 case of abnormal baseline had blood stained liquor. Out of 3 cases with non-reassuring baseline 2 had thick meconium (66.67\%) and 1 (33.33\%) had clear liquor. Out of 245 cases of reassuring baseline heart rate, 133 (54.29\%) cases had clear liquor. Inspite of the base line heart rate being reassuring, 68 (27.76\%) cases had thin meconium and 44 (17.96\%) cases had thick meconium (Table 2). So positive predictive value, negative predictive value, sensitivity and specificity were $75 \%, 59 \%, 99 \%, 2.6 \%$ respectively. It was assumed that baseline heart rate was not a good indicator of abnormal 
liquor colour. Out of 249 cases, 121 babies had Apgar score at $1 \mathrm{~min}<7$ which is $48.59 \%$ and $128(51.41 \%)$ babies had normal Apgar score. All the abnormal baseline heart rates had babies with Apgar score at $1 \mathrm{~min}$ $<7$ and all the non-reassuring baseline had Apgar score $<7$. At the same time 117 babies with reassuring baseline had Apgar score at $1 \mathrm{~min}<7$. So positive predictive value, negative predictive value, specificity and sensitivity of baseline heart rate for Apgar score at $1 \mathrm{~min}$ were $100 \%, 59 \%, 100 \%, 3.3 \%$ respectively. Similarly, $66.67 \%$ of the non-reassuring baseline heart rate had Apgar score at $5 \mathrm{~min}<7$ and $92.65 \%$ of reassuring baseline heart rates had normal Apgar score at $5 \mathrm{~min}$. It also showed that out of 121 babies with abnormal Apgar score at $1 \mathrm{~min}$ reduce to only 20 at $5 \mathrm{~min}$. Positive predictive value of baseline heart rate for Apgar score at 5 min was $50 \%$, negative predictive value was $91.9 \%$, specificity $(99.1 \%)$ and sensitivity (10\%) (Table 3).

Table 2: Relation between baseline heart rates and colour of liquor.

\begin{tabular}{|llll|}
\hline Liquor colour & Baseline & Non reassuring & Reassuring \\
\hline Blood stained, $\mathrm{n}=1(0.40 \%)$ & Abnormal & 0 & 0 \\
\hline Thick meconium, $\mathrm{n}=46(18.47 \%)$ & $1(100 \%)$ & $2(66.67 \%)$ & $44(17.96 \%)$ \\
\hline Thin meconium, $\mathrm{n}=68(27.31 \%)$ & 0 & 0 & $68(27.76 \%)$ \\
\hline Clear, $\mathrm{n}=134(53.82 \%)$ & 0 & $1(33.33 \%)$ & $133(54.29 \%)$ \\
\hline Total no. of cases & 0 & $\mathbf{3}$ & $\mathbf{2 4 5}$ \\
\hline
\end{tabular}

Table 3: Relation of baseline heart rate with Apgar score at $1 \mathrm{~min}$ and at $5 \mathrm{~min}$.

\begin{tabular}{|llll|}
\hline APGAR score 1 min & Baseline & Non reassuring & Reassuring \\
\hline$<7, \mathrm{n}=121(48.59 \%)$ & Abnormal & $3(100 \%)$ & $117(47.76 \%)$ \\
\hline Normal, $\mathrm{n}=128(51.41 \%)$ & $1(100 \%)$ & 0 & $128(52 \%)$ \\
\hline Total no. of cases & 0 & $\mathbf{3}$ & $\mathbf{2 4 5}$ \\
\hline APGAR score 5 min & $\mathbf{1}$ & & $18(7.35 \%)$ \\
\hline Less than 7, $\mathrm{n}=20(8 \%)$ & & $2(66.67 \%)$ & $227(92.65 \%)$ \\
\hline Normal, $\mathrm{n}=229(91.96 \%)$ & 0 & $1(33.33 \%)$ & \\
\hline
\end{tabular}

Table 4: Relationship with baseline heart rates with INCU admission and >10 days hospital stay.

\begin{tabular}{|c|c|c|c|}
\hline \multirow{2}{*}{ Admission in INCU } & \multicolumn{3}{|l|}{ Baseline } \\
\hline & Abnormal & Non reassuring & Reassuring \\
\hline No, $n=132(53.87 \%)$ & 0 & 0 & $132(53.88 \%)$ \\
\hline Yes, $n=117(47.75 \%)$ & $1(100 \%)$ & $3(100 \%)$ & $113(46.12 \%)$ \\
\hline Total no. of cases & 1 & 3 & 245 \\
\hline \multicolumn{4}{|l|}{$>10$ days stay } \\
\hline No, $n=211(84.74 \%)$ & $1(100 \%)$ & 0 & $210(85.71 \%)$ \\
\hline Yes, $n=38(15.26 \%)$ & 0 & $3(100 \%)$ & $35(14.29 \%)$ \\
\hline Total no. of cases & 1 & 3 & 245 \\
\hline
\end{tabular}

A total of 117 babies were needed NICU admission and only 38 babies stayed for more than 10 days. All the babies with abnormal and non-reassuring baseline required NICU admission and more than 10 days stay. So, predictive value of abnormal and non-reassuring heart rates was $100 \%$. 113 cases with reassuring baselines also needed INCU stay and 35 babies needed more than 10 days stay meaning there being other abnormality in the CTG and only reassuring baseline could'nt predict the fetal well-being. Positive predictive value, negative predictive value, specificity and sensitivity of baseline heart rate for NICU admission were 100\%, 53.8\% 100\%
$3.41 \%$ respectively. Positive predictive value for $>10$ days hospital stay was $75 \%$, negative predictive value was $85.71 \%$ specificity was $99.52 \%$ and sensitivity was $7.8 \%$ (Table 4). Out of 7 cases with abnormal variability 1 had blood stained liquor, 3 cases had thick meconium and 3 cases had thin meconium meaning a very poorer correlation between the two. Out of 41 cases with nonreassuring variability, $22(53.66 \%)$ cases had thick meconium showing a fairly good predictive value of abnormal liquor colour. Out of 201 cases with reassuring, $124(61.69 \%)$ cases had clear liquor. So, positive predictive value of the variability for liquor colour was 
$79.2 \%$ and negative predictive value was $61.7 \%$, specificity was $92.53 \%$ and sensitivity was $33 \%$ (Table
5).

Table 5: Relation of variability with liquor colour.

\begin{tabular}{|llll|}
\hline Liquor colour & Variability & & Non reassuring \\
\hline Blood stained, $\mathrm{n}=1(0.40 \%)$ & Abnormal & 0 & 0 \\
\hline Thick meconium, $\mathrm{n}=46(18.47 \%)$ & $1(14.29 \%)$ & $22(53.66 \%)$ & $21(10.45 \%)$ \\
\hline Thin meconium, $\mathrm{n}=68(27.31 \%)$ & $3(42.86 \%)$ & $12(29.27 \%)$ & $56(27.86 \%)$ \\
\hline Clear, $\mathrm{n}=134(53.82 \%)$ & 0 & $7(17.07 \%)$ & $124(61.69 \%)$ \\
\hline Grand total & $3(42.86 \%)$ & $\mathbf{4 1}$ & $\mathbf{2 0 1}$ \\
\hline
\end{tabular}

Table 6: Relation of variability with Apgar score at 1 min and 5 min.

\begin{tabular}{|llll|}
\hline APGAR score 1 min & Variability & Non reassuring & Reassuring \\
\hline$<7, \mathrm{n}=121(48.59 \%)$ & Abnormal & $38(92.68 \%)$ & $76(37.81 \%)$ \\
\hline Normal, $\mathrm{n}=128(51.41 \%)$ & $7(100 \%)$ & $3(7.31 \%)$ & $125(62.18 \%)$ \\
\hline Total no. of cases & 0 & $\mathbf{4 1}$ & $\mathbf{2 0 1}$ \\
\hline APGAR score 5 min & $\mathbf{7}$ & & $5(2.49 \%)$ \\
\hline Less than 7, $\mathrm{n}=20(8 \%)$ & $4(57.14 \%)$ & $11(26.83 \%)$ & $196(97.51 \%)$ \\
\hline Normal, $\mathrm{n}=229(91.96 \%)$ & $3(42.86 \%)$ & $30(73.17 \%)$ & \\
\hline
\end{tabular}

Table 7: Relation of variability with INCU admission and >10 days INCU stay.

\begin{tabular}{|c|c|c|c|}
\hline \multirow{2}{*}{ Admission in INCU } & \multicolumn{3}{|l|}{ Variability } \\
\hline & Abnormal & Non reassuring & Reassuring \\
\hline No, $n=132(53.02 \%)$ & 0 & $6(14.63 \%)$ & $126(62.69 \%)$ \\
\hline Yes, $n=117(46.98 \%)$ & $7(100 \%)$ & $35(85.37 \%)$ & $75(37.31 \%)$ \\
\hline Total no. of cases & 7 & 41 & 201 \\
\hline >10 days NICU stay & Abnormal & Non reassuring & Reassuring \\
\hline No, $n=211(84.74 \%)$ & $2(28.5 \%)$ & $25(61 \%)$ & $184(91.5 \%)$ \\
\hline Yes, $n=38(15.26 \%)$ & $5(71.5 \%)$ & $16(39 \%)$ & $17(8.5 \%)$ \\
\hline Total no. of cases & 7 & 41 & 201 \\
\hline
\end{tabular}

Table 8: Relation of deceleration with liquor colour.

\begin{tabular}{|llll|}
\hline \multirow{2}{*}{ Liquor colour } & Abnormal deceleration & & SPD \\
\hline Blood stained, $\mathrm{n}=1(0.4 \%)$ & AVD & LD & $1(1.61 \%)$ \\
\hline Thick meconium, $\mathrm{n}=46(18.47 \%)$ & 0 & 0 & $24(38.71 \%)$ \\
\hline Thin meconium, $\mathrm{n}=68(27.31 \%)$ & $18(10.40 \%)$ & $4(28.57 \%)$ & $13(20.97 \%)$ \\
\hline Clear, $\mathrm{n}=134(53.82 \%)$ & $51(29.48 \%)$ & $4(28.57 \%)$ & $24(38.71 \%)$ \\
\hline Total no. of cases & $104(60.12 \%)$ & $6(42.86 \%)$ & 62 \\
\hline
\end{tabular}

When compared with Apgar score, positive predictive value, negative predictive value, specificity and sensitivity of variability for Apgar score at 1 min was $93.8 \%, 62.2 \%, 97.7 \%$ and $37.2 \%$ respectively whereas for Apgar score at $5 \mathrm{~min}$ were $39.47 \%$, 97.5\%, 85.65 and $50 \%$ respectively (Table 6 ). It was observed that out of 117 INCU admissions 75 babies had reassuring variability. Out of 38 babies needing $>10$ days stay, 17
$(8.5 \%)$ babies had reassuring variability, $16(39 \%)$ had non reassuring variability and $5(71.5 \%)$ had abnormal variability. So positive predictive value of variability for INCU admission was $89.4 \%$, negative predictive value was $62.7 \%$, specificity was $96.2 \%$ sensitivity was $35.9 \%$. Positive predictive value for $>10$ days stay was $43.8 \%$, negative predictive value was $91.54 \%$, specificity was $87.2 \%$ and sensitivity was $55.26 \%$ (Table 7). Out of 173 
cases with atypical variable deceleration, 104 (60.12\%) cases had clear liquor, 69 cases had meconium stained liquor, so positive predictive value being $39.9 \%$, negative predictive value $39.5 \%$, specificity was $22.4 \%$ and sensitivity was $59.48 \%$. Positive predictive value, negative predictive value, specificity and sensitivity of late deceleration were $57.1 \%, 54.5 \%, 95.5 \%$ and $6.95 \%$ respectively. Positive predictive value of single prolonged deceleration for abnormal liquor was $61.3 \%$, negative predictive value was $58.8 \%$, specificity was $82.1 \%$ (Table 8 ).

Table 9: Relation of deceleration with Apgar score at 1 min and 5 min.

\begin{tabular}{|llll|}
\hline APGAR score 1 min & Deceleration & & LD \\
\hline$<7, \mathrm{n}=121(48.59 \%)$ & AVD & $10(71.43 \%)$ & $56(90.32 \%)$ \\
\hline Normal, $\mathrm{n}=128(51.41 \%)$ & $55(31.79 \%)$ & $4(28.57 \%)$ & $6(9.68 \%)$ \\
\hline Total no. of cases & $118(68.21 \%)$ & $\mathbf{1 4}$ & $\mathbf{6 2}$ \\
\hline APGAR score 5 min & $\mathbf{1 7 3}$ & & $14(22.58 \%)$ \\
\hline Less than 7, $\mathrm{n}=20(8 \%)$ & & $2(14.29 \%)$ & $48(77.42 \%)$ \\
\hline Normal, $\mathrm{n}=229(91.96 \%)$ & $4(2.31 \%)$ & $12(85.71 \%)$ & $\mathbf{6 2}$ \\
\hline Grand total & $169(97.69 \%)$ & $\mathbf{1 4}$ & $\mathbf{6}$ \\
\hline
\end{tabular}

Table 10: Relation of deceleration with INCU admission and >10 days INCU stay.

\begin{tabular}{|c|c|c|c|}
\hline \multirow{2}{*}{ Admission in INCU } & \multicolumn{3}{|l|}{ Deceleration } \\
\hline & AVD & LD & SPD \\
\hline No, $n=132(53.02 \%)$ & $121(69.94 \%)$ & $4(28.57 \%)$ & $7(11.29 \%)$ \\
\hline Yes, $n=117(46.98 \%)$ & $52(30.06 \%)$ & $10(71.43 \%)$ & $55(88.71 \%)$ \\
\hline Total no. of cases & 173 & 14 & 62 \\
\hline \multicolumn{4}{|l|}{$>10$ days INCU stay } \\
\hline No, $n=211(84.74 \%)$ & $162(93.64 \%)$ & $12(85.71 \%)$ & $37(59.68 \%)$ \\
\hline Yes, $n=38(15.26 \%)$ & $11(6.36 \%)$ & $2(14.29 \%)$ & $25(40.32 \%)$ \\
\hline
\end{tabular}

Table 11: Relation of acceleration with liquor colour.

\begin{tabular}{|lll|}
\hline Liquor colour & Acceleration & Reassuring \\
\hline Blood stained, $\mathrm{n}=1(0.40 \%)$ & Abnormal & 0 \\
\hline Thick meconium, $\mathrm{n}=46(18.47 \%)$ & $1(068 \%)$ & $9(8.74 \%)$ \\
\hline Thin meconium, $\mathrm{n}=68(27.31 \%)$ & $37(25.34 \%)$ & $28(27.18 \%)$ \\
\hline Clear, $\mathrm{n}=134(53.82 \%)$ & $40(27.40 \%)$ & $66(64.08 \%)$ \\
\hline Total no. of cases & $68(46.58 \%)$ & 103 \\
\hline
\end{tabular}

Table 12: Relation of acceleration with Apgar score at 1 min and 5 min.

\begin{tabular}{|lll|}
\hline APGAR score 1 min & $\begin{array}{l}\text { Deceleration } \\
\text { Abnormal }\end{array}$ & Reassuring \\
\hline$<7, \mathrm{n}=121(48.59 \%)$ & $87(59.59 \%)$ & $34(33.01 \%)$ \\
\hline Normal, $\mathrm{n}=128(51.41 \%)$ & $59(40.41 \%)$ & $69(66.99 \%)$ \\
\hline Total no. of cases & $\mathbf{1 4 6}$ & $\mathbf{1 0 3}$ \\
\hline APGAR score 5 min & & $3(2.91 \%)$ \\
\hline Less than 7, $\mathrm{n}=20(8 \%)$ & $17(11.64 \%)$ & $100(97.09 \%)$ \\
\hline Normal, $\mathrm{n}=229(91.96 \%)$ & $129(88.36 \%)$ & \\
\hline
\end{tabular}

When deceleration was compared with NICU stay, positive predictive value of atypical variable deceleration, late deceleration and single prolonged deceleration for
Apgar at $1 \mathrm{~min}$ were $31.79 \%, 71.43 \%$ and $90.32 \%$ respectively and for Apgar at 5min were 2.23\%, $14.28 \%$ and $22.58 \%$ respectively. Negative predictive value of 
atypical variable deceleration, late deceleration and single prolonged deceleration for Apgar at $1 \mathrm{~min}$ are 13.15\%, $52.8 \%$ and $65.4 \%$ respectively and for Apgar at 5 min are $78.9 \%, 92.5 \%$ and $96.8 \%$ respectively. Specificity of AVD, LD and SPD were $7.8 \%, 96.9 \%$ and $95.4 \%$ respectively and for 5 min Apgar are 26.2\%, 94.8\% and $79 \%$ respectively. Sensitivity of AVD, LD and SPD for 1 min Apgar are $45.5 \%, 8.3 \%$ and $46.3 \%$ respectively and that for Apgar at 5min were $20 \%, 10 \%$ and $70 \%$ respectively (Table 9).

Table 13: Relation of acceleration with INCU admission.

\begin{tabular}{|lll|}
\hline Admission in INCU & Acceleration & Reassuring \\
\hline No, $n=132(53.02 \%)$ & Abnormal & $71(68.93 \%)$ \\
\hline Yes, $\mathrm{n}=117(46.98 \%)$ & $61(41.78 \%)$ & $32(31.07 \%)$ \\
\hline Total no. of cases & $85(58.22 \%)$ & $\mathbf{1 0 3}$ \\
\hline$>\mathbf{1 0}$ days INCU stay & $\mathbf{1 4 6}$ & $96(93.20 \%)$ \\
\hline No, $\mathrm{n}=211(84.74 \%)$ & & $7(6.80 \%)$ \\
\hline Yes, $\mathrm{n}=38(15.26 \%)$ & $115(78.77 \%)$ & \\
\hline
\end{tabular}

Table 14: Relationship of mode of delivery with baseline, variability, deceleration and acceleration.

\begin{tabular}{|c|c|c|c|c|c|c|c|c|c|c|c|}
\hline \multirow{2}{*}{ Mode of delivery } & \multicolumn{3}{|c|}{ Baseline } & \multicolumn{3}{|c|}{ Variability } & \multicolumn{3}{|c|}{ Deceleration } & \multicolumn{2}{|c|}{ Acceleration } \\
\hline & $\mathbf{A}$ & NR & $\mathbf{R}$ & $\mathbf{A}$ & NR & $\mathbf{R}$ & AVD & LD & SPD & $\mathbf{A}$ & $\mathbf{R}$ \\
\hline $\begin{array}{l}\text { Em LSCS, } \\
\mathrm{n}=181,(72.69 \%)\end{array}$ & $\begin{array}{l}1 \\
100 \%\end{array}$ & 1 & $\begin{array}{l}179 \\
73.06 \%\end{array}$ & $\begin{array}{l}5 \\
71.43 \%\end{array}$ & $\begin{array}{l}24 \\
58.54 \%\end{array}$ & $\begin{array}{l}152 \\
75.62 \%\end{array}$ & $\begin{array}{l}151 \\
87.28 \%\end{array}$ & $\begin{array}{l}2 \\
14.29 \%\end{array}$ & $\begin{array}{l}28 \\
45.16 \%\end{array}$ & $\begin{array}{l}109 \\
74.66 \%\end{array}$ & $\begin{array}{l}72 \\
69.90 \%\end{array}$ \\
\hline $\begin{array}{l}\text { Forceps delivery, } \\
\mathrm{n}=24,(9.64 \%)\end{array}$ & 0 & $\begin{array}{l}1 \\
33.33 \%\end{array}$ & $\begin{array}{l}23 \\
9.38 \%\end{array}$ & $\begin{array}{l}2 \\
28.57 \%\end{array}$ & $\begin{array}{l}7 \\
17.08 \%\end{array}$ & $\begin{array}{l}15 \\
7.46 \%\end{array}$ & $\begin{array}{l}2 \\
1.16 \%\end{array}$ & $\begin{array}{l}8 \\
57.14 \%\end{array}$ & $\begin{array}{l}14 \\
22.31 \%\end{array}$ & $\begin{array}{l}14 \\
9.59 \%\end{array}$ & $\begin{array}{l}10 \\
9.71 \%\end{array}$ \\
\hline $\begin{array}{l}\text { Vaginal delivery } \\
\mathrm{n}=44,(17.6 \%)\end{array}$ & 0 & $\begin{array}{l}1 \\
33.33 \%\end{array}$ & $\begin{array}{l}43 \\
17.55 \%\end{array}$ & 0 & $\begin{array}{l}10 \\
24.39 \%\end{array}$ & $\begin{array}{l}34 \\
16.92 \%\end{array}$ & $\begin{array}{l}20 \\
11.565\end{array}$ & $\begin{array}{l}4 \\
28.57 \%\end{array}$ & $\begin{array}{l}20 \\
32.26 \%\end{array}$ & $\begin{array}{l}23 \\
15.75 \%\end{array}$ & $\begin{array}{l}21 \\
20.39 \%\end{array}$ \\
\hline Total no. of cases & 1 & 3 & 245 & 7 & 41 & 201 & 173 & 14 & 62 & 146 & 103 \\
\hline
\end{tabular}

Table 15: Relation of liquor colour with Apgar score-1 min and 5 min.

\begin{tabular}{|lllll|}
\hline A PGAR score-1 min & Liquor color & & Thick meconium & Thin meconium \\
\hline$<7, \mathrm{n}=121(48.59 \%)$ & Blood stained & Clear & $41(89.1 \%)$ & $34(50.0 \%)$ \\
\hline Normal, $\mathrm{n}=128(51.41 \%)$ & 0 & $45(33.6 \%)$ & $5(10.9 \%)$ & $34(50.0 \%)$ \\
\hline Grand total & $\mathbf{1}$ & $89(66.4 \%)$ & $\mathbf{4 6}$ & $\mathbf{6 8}$ \\
\hline Apgar score at 5min & & $\mathbf{1 3 4}$ & & $1(1.5 \%)$ \\
\hline$<7, \mathrm{n}=20(8.03 \%)$ & 0 & $6(4.5 \%)$ & $13(28.3 \%)$ & $67(98.5 \%)$ \\
\hline Normal, $\mathrm{n}=229(91.96 \%)$ & $1(100 \%)$ & $128(95.5 \%)$ & $33(71.7 \%)$ & \\
\hline
\end{tabular}

Table 16: Relation of liquor colour with INCU admission and >10 days INCU stay.

\begin{tabular}{|c|c|c|c|c|}
\hline \multirow{2}{*}{ Admission in INCU } & \multicolumn{4}{|l|}{ Liquor color } \\
\hline & Blood stained & Clear & Thick meconium & Thin meconium \\
\hline No, $n=132(53.1 \%)$ & 0 & $93(69.4 \%)$ & $6(13.0 \%)$ & $33(48.5 \%)$ \\
\hline Yes, $n=117(46.9 \%)$ & $1(100 \%)$ & $41(30.6 \%)$ & $40(87.0 \%)$ & $35(51.5 \%)$ \\
\hline Grand total & 1 & 134 & 46 & 68 \\
\hline \multicolumn{5}{|l|}{ >10 days INCU stay } \\
\hline No, $n=211(84.74 \%)$ & $1(100 \%)$ & $120(89.6 \%)$ & $26(56.5 \%)$ & $64(94.1 \%)$ \\
\hline Yes, $n=38(15.26 \%)$ & 0 & $14(10.4 \%)$ & $20(43.5 \%)$ & $4(5.9 \%)$ \\
\hline
\end{tabular}

Relation of deceleration with INCU admission and $>10$ days INCU stay showed that positive predictive value of single prolonged deceleration was maximum both for INCU stay and >10 days stay i.e, $88.7 \%$ and $40.32 \%$ respectively, followed by that of late deceleration $71.42 \%$ and $14.3 \%$ respectively and that of atypical variable deceleration $30 \%$ and $6.4 \%$ respectively. Negative predictive value of single prolonged deceleration was 
maximum for INCU and $>10$ days stay was $66.84 \%$ and $93 \%$, that of late deceleration was $54.5 \%$ and $84.7 \%$ and that of atypical variable deceleration was $14.5 \%$ and $64.5 \%$. Specificity of single prolonged deceleration for INCU and $>10$ days stay was $94.7 \%$ and $94.31 \%$, that of late deceleration was $96.9 \%$ and $94.3 \%$ and that of atypical variable deceleration was very low $(8.3 \%$ and $23.2 \%$ ). Sensitivity of SPD, AVD and LD were low for INCU admission i.e, $47 \%, 44.4 \%$ and $8.5 \%$ and that for $>10$ days stay were $65.8 \%, 29 \%$ and $5.3 \%$ (Table 10). Relation of acceleration with liquor colour showed that the positive predictive value of absence of acceleration for abnormal liquor colour was $53.4 \%$ negative predictive value was $64.1 \%$, specificity was $49.3 \%$ and sensitivity was $67.8 \%$ (Table 11). Similarly Absence of acceleration for Apgar of babies at $1 \mathrm{~min}$ had positive predictive value of $59.6 \%$, negative predictive value of $67 \%$, and specificity of $53.9 \%$ and sensitivity of $71.9 \%$.Positive predictive value of absence of acceleration for Apgar score at 5 min was very low $11.6 \%$, negative predictive value was $97.1 \%$, specificity was $43.7 \%$ and sensitivity was $85 \%$ (Table 12). Positive predictive value of absence of acceleration for NICU admission was $58.2 \%$, negative predictive value was $68.9 \%$, specificity was $53.8 \%$ and sensitivity was $72.6 \%$. The negative predictive value of acceleration for $>10$ days hospital stay was $93.2 \%$ and sensitivity was $81.6 \%$ but positive predictive value and specificity were very low (Table 13).

Table 17: Relation of mode of delivery with Apgar score-1min and 5 min.

\begin{tabular}{|c|c|c|c|c|}
\hline \multirow{2}{*}{ APGAR score-1 min } & \multicolumn{4}{|c|}{ Mode of delivery } \\
\hline & Em. LSCS & Low forceps & Outlet forceps & Vaginal delivery \\
\hline$<7, \mathrm{n}=121(48.59 \%)$ & $72(39.78 \%)$ & $5(71.43 \%)$ & $14(82.35 \%)$ & $30(68.18 \%)$ \\
\hline Normal, $n=128(51.41 \%)$ & $109(60.22 \%)$ & $2(28.57 \%)$ & $3(17.65 \%)$ & $14(31.82 \%)$ \\
\hline Grand total & 181 & 7 & 17 & 44 \\
\hline \multicolumn{5}{|l|}{ Apgar score at $5 \mathrm{~min}$} \\
\hline$<7, n=20(8.03 \%)$ & $6(3.31 \%)$ & $3(42.86 \%)$ & $6(35.29 \%)$ & $5(11.36 \%)$ \\
\hline Normal, $n=229(91.96 \%)$ & $175(96.69 \%)$ & $4(57.14 \%)$ & $11(64.71 \%)$ & $39(88.64 \%)$ \\
\hline
\end{tabular}

Table 18: Relation of mode of delivery with INCU admission and >10 days INCU stay.

\begin{tabular}{|lllll|}
\hline Admission in INCU & Mode of delivery & Low forceps & Outlet forceps & Vaginal delivery \\
\hline No, $\mathrm{n}=132(53.1 \%)$ & $116(64.09 \%)$ & $2(28.57 \%)$ & $3(17.65 \%)$ & $11(25 \%)$ \\
\hline Yes, $\mathrm{n}=117(46.9 \%)$ & $65(35.91 \%)$ & $5(71.43 \%)$ & $14(82.35 \%)$ & $33(75 \%)$ \\
\hline Grand total & $\mathbf{1 8 1}$ & $\mathbf{7}$ & $\mathbf{1 7}$ & $\mathbf{4 4}$ \\
\hline$>\mathbf{1 0}$ days INCU stay & & & & $35(79.55 \%)$ \\
\hline No, $\mathrm{n}=210(8.3 \%)$ & $164(90.61 \%)$ & $4(57.14 \%)$ & $8(47.06 \%)$ & $9(20.45 \%)$ \\
\hline Yes, $\mathrm{n}=35(14.1 \%)$ & $17(9.39 \%)$ & $3(42.86 \%)$ & $9(52.94 \%)$ & \\
\hline
\end{tabular}

Out of 245 cases with reassuring baselines $179(73.06 \%)$ cases had cesarean section, only $43(17.55 \%)$ had normal vaginal delivery and $23(9.38 \%)$ cases had operative vaginal delivery. Out of 3 cases with non-reassuring baselines, 1 had vaginal delivery, 1 had cesarean section and 1 had outlet forceps delivery. Out of 181 cases that had emergency cesarean section $152(75.62 \%)$ cases had reassuring variability only $5(71.43 \%)$ had abnormal variability and $24(58.54 \%)$ had non reassuring. Total of 146 cases had absence of acceleration, of which $74.66 \%$ required emergency cesarean section, $14(9.59 \%)$ had operative vaginal delivery and $15.75 \%$ had vaginal delivery. We also found out of 173 cases with atypical variable deceleration $151(87.28 \%)$ cases had emergency cesarean section, out of 14 cases with late deceleration, 2 (14.29\%) had emergency cesarean section, 8 (57.14\%) cases had instrumental vaginal delivery. Out of 62 cases with single prolonged deceleration $28(45.16 \%)$ cases had emergency cesarean section, $14(9.59 \%)$ cases had instrumental vaginal delivery (Table 14). The positive predictive value of liquor colour for Apgar score at $1 \mathrm{~min}$ was $66.1 \%$, negative predictive value was $66.4 \%$, specificity was $69.5 \%$ and sensitivity was $62.8 \%$. The positive predictive value of liquor for Apgar score at 5 min was very poor only $66.1 \%$, negative predictive value was $66.4 \%$, specificity was $69.5 \%$ and sensitivity was $62.8 \%$ (Table 15). Positive predictive value of liquor for admission in NICU was $66.1 \%$, negative predictive value was $69.4 \%$, specificity was $70.5 \%$ and sensitivity was $65 \%$. The positive predictive value of liquor colour for hospital stay $>10$ days was $22.95 \%$, negative predictive value was $89.65 \%$, specificity was $59.7 \%$ and sensitivity was $63.2 \%$ (Table 16). Out of 181 cases that had cesarean section for some abnormal heart rate feature, 109 cases $(60.2 \%)$ had babies with normal Apgar score 1 min and 175 cases $(96.7 \%)$ had babies with normal Apgar score 5 
min. Similarly, $2(28.57 \%)$ cases of low forceps and 4 $(57.14 \%)$ cases of outlet forceps had normal Apgar at 1 min and 5 min respectively. Among the vaginal delivery cases, $14(31.82 \%)$ cases and $39(88.64 \%)$ cases had normal Apgar at $1 \mathrm{~min}$ and $5 \mathrm{~min}$ respectively (Table 17). When compared relation of mode of delivery with NICU admission and $>10$ days NICU stay we found that out of 181 cases, which had cesarean section for some abnormal heart rate feature, 116 cases $(64.1 \%)$ had babies who did not require any INCU admission and 164 cases $(90.6 \%)$ had babies who did not require more than 10 days hospital stay (Table 18).

\section{DISCUSSION}

A total of 249 women were selected randomly out of which, 181 women had cesarean section for abnormal heart rate features qualifying the CTG as a pathological (RCOG 2001). Total 128 women (48.59\%) had babies with Apgar score at $1 \mathrm{~min}<7$, only 20 babies $(8 \%)$ had Apgar score at $5 \mathrm{~min}<7$. Total 117 babies $(47.8 \%)$ required INCU admission and only 35 babies (14\%) required more than 10 days hospital stay. Our studies showed increased risk of maternal morbidity due to emergency cesarean section. Only 35 babies with $>10$ days hospital stay were considered to have increased neonatal morbidity.

Other studies had also shown intrapartum fetal asphyxia as an important cause of still birth and neonatal death. Most fetuses tolerate intrauterine hypoxia during labour and were delivered without complications but assessment suggesting fetal distress were associated with an increased likelihood of cesarean section. ${ }^{5}$

\section{Accuracy of the screening}

In our study, accuracy of pathological CTG or the four abnormal heart rate features were assessed by the negative predictive values and specificity. The negative predictive values and specificities of all the heart rate features were $>60 \%$ except for the atypical variable deceleration, in detecting all the parameters of adverse perinatal outcome in our study. As a screening test the sensitivity and positive predictive values should be more. The sensitivities of the baseline, variability, deceleration and acceleration in detecting adverse perinatal outcome were very low, when each abnormal heart rate pattern was taken individually. Thus, the sensitivity of pathological CTG was found to be poor. This may be due to two factors that may limit the accuracy and reliability i.e. the method used to measure fetal heart activity and the variability associated with CTG interpretations.

Other studies had shown that an abnormal CTG trace occurs in up to $50 \%$ of all recordings, but only a small proportion of these fetuses were at risk of hypoxia. ${ }^{6}$ Abnormal deceleration in FHR and decrease in variability during uterine contraction were considered to be suggestive of fetal distress but the patterns were not diagnostic. In addition, normal or equivocal fetal heart rate patterns did not exclude the diagnosis of fetal distress. Precise information on the frequency of the false negative and false positive results was lacking due to absence of an acceptable definition of fetal distress. ${ }^{7}$

\section{Effectiveness of early detection}

Out of 249 cases with abnormal heart rate features either individually or in combination, we could detect 128 (48.6\%) babies with poor Apgar score at 1 min of which $20(8 \%)$ still had a poor Apgar score at $5 \mathrm{~min}$. So, we were able to save these 128 babies from detoriating further and landing up in cerebral palsy or intrapartum still birth or early neonatal death. But we did not follow up the babies or mothers. It was true that we could detect early but how effectively what was the long-term benefit could not be assessed in our study. In Greece, a trial carried out in predominantly low risk women found no difference in most neonatal outcome but reported a significant decrease in perinatal mortality.

The neonatal seizure prevented by CTG may not be those associated with long term impairment. At 4 year follow up after seizures in the Dublin trial, the total no and rate of cerebral palsy were identical in monitored and controlled groups. ${ }^{8}$ A follow up study of the growth and development at 9 months of age infants involved in the second Denver trial failed to show any long-term benefits of CTG.

\section{CTG leads to an increase in obstetric interventions}

Out of 249 cases, 181 (73\%) had cesarean section. An increase in cesarean section rate and operative vaginal deliveries by more than $50 \%$ in comparison to the era when there was no CTG machine in our hospital. This finding was pertinent with Dundee study, cochrane review (2002), which also showed increased cesarean section rate (RR 1.41), operative vaginal delivery (RR 1.20). ${ }^{9}$ But the Dublin study showed no increase in operative deliveries by use of admission CTG. ${ }^{10} \mathrm{~A}$ randomized study in the seventies and eighties had demonstrated a higher incidence of artificial deliveries when CTG was compared with dedicated intermittent auscultation. ${ }^{11}$ The addition of the cord blood sampling and fetal scalp blood $\mathrm{pH}$ to assess the fetal acid base status in a case of suspected or abnormal fetal heart rate patterns clearly reduces the number of obstetric intervention if compared with the application of CTG alone. $^{12}$

There was also a correlation between liquor colour and adverse perinatal outcome. Meconium stained liquor had a sensitivity and specificity for Apgar score at $1 \mathrm{~min}$ of $69.5 \%$ and $62.8 \%$ respectively. Our study showed a positive correlation between meconium and heart rate patterns. This was also shown in various other studies. If the CTG was pathological, the presence of meconium was associated with significantly higher chance of a baby 
being acidotic, born in poor condition and needing resuscitation. ${ }^{3,13}$ Meis et al, prospectively evaluated 2923 pregnancies and documented a statistically significant increase in fetal heart rate abnormalities, depressed Apgar scores, and even neonatal death in labours complicated by early heavy meconium. Fenton and Steer in their study concluded that variation in FHR without meconium and the passage of meconium without change in FHR were not true indicators of fetal distress. In our study single prolonged deceleration had maximum specificity, sensitivity, positive predictive value and negative predictive value for meconium staining liquor compared to atypical variable deceleration and late deceleration. But late deceleration exceptionally had a high specificity for meconium staining.

There was a correlation between fetal heart rate patterns and Apgar score. Baseline, variability and deceleration had a good specificity, avg $>80 \%$ and acceleration had a good sensitivity for Apgar score at $1 \mathrm{~min}$ and $5 \mathrm{~min}$. The predictive value of a normal FHR pattern in detecting a neonate with Apgar score $>7$ was 99\%. The abnormal FHR pattern predicted a depressed neonate with $67 \%$ accuracy. The FHR was normal in $98 \%$ of neonates with Apgar score more than 7. A normal FHR pattern could also be seen in neonate with Apgar scores $<7$ but less frequent, representing a sensitivity of $77 \%$.

\section{High intra and inter observer variability}

This factor was profound, because of changing registrars in different shifts of duty and their varied opinion regarding the CTG tracings. Reading, classification and interpretation should be the successive steps in the assessment of CTG tracings. Often a conclusion was reached in vague terms of suspicious, pathologic, ominous or terminal FHR pattern. The high inter or intra observer variability concerning the classification and interpretation of FHR pattern had been substantiated in a large no of publication. ${ }^{14}$

\section{The low validity, high false positive rate}

Our study showed that the sensitivity of the various abnormal heart rate features was very low, $<20 \%$ for most of them, so false positive rates were high for abnormal heart rate features taken individually in a pathological CTG. It may be due to small sample size, and absence of confirmation of fetal distress by detection of acidosis by scalp blood $\mathrm{PH}$ or long term follow up.

There is no significant correlation of fetal heart rate patterns and perinatal outcome were found with maternal age, parity, fetal gender or baby weight which were in agreement with studies by Mahomed K et al. ${ }^{15}$

The main limitation of our study was that it was an observational study. Normal CTG has not been studied. There was interobserver variability markedly. The study was biased by patient relatives demand for early intervention. Perinatal outcome was assessed by liquor colour, Apgar score, and INCU stay which were all subjective parameters and also suffered from interobserver variations. Follow up study for assessing long term effects of babies were not done.

\section{CONCLUSION}

We concluded that, the abnormal fetal heart rate features in a CTG, (RCOG 2001) were related to the adverse perinatal outcomes, meconium staining of liquor, Apgar score $<7$ at $1 \mathrm{~min}$ and $5 \mathrm{~min}$ after delivery, INCU admission and hospital stay $>10$ days. The specificities and sensitivities of each abnormal heart rate feature to detect adverse perinatal outcome differ when considered individually. Large study samples and addition of current modalities of intrapartum fetal monitoring can reduce the limitations of our study. So, abnormal fetal heart rate features in a intrapartum CTG of a labouring mother $>37$ weeks can detect fetuses in distress with different sensitivity and specificity when considered individually.

\section{ACKNOWLEDGMENTS}

Authors would like to thank Dr. Sajal Dutta, Prof. Department of Obstetrics and Gynecology who guided me for the study and helped me preparing the manuscript.

Funding: No funding sources

Conflict of interest: None declared

Ethical approval: The study was approved by the Institutional Ethics Committee

\section{REFERENCES}

1. Parer JT, Livingston EG. What is fetal distress? Am J Obstet Gynecol. 1990;162(6):1421-7.

2. Dastur AE. Intrapartum fetal distress. J Obstet Gynecol India. 2005;55(2):115-7.

3. Gorzelac L, Czajkowska EP, Oleszczuk J. Intrapartum cardiotocography and fetal pulse oximetry in assessing fetal hypoxia. Int $\mathbf{J}$ Gynecol Obstet. 2002;76:9-14.

4. Vardhan S, Bhattacharya TK, Kathpalia SK, Kochar SPS. Intrapartum electronic fetal monitoring: Does it lead or mislead? MJAFI. 2006;62:51-2.

5. Cunningham G, Norman F, Kenneth J. Intrapartum Assessment: Williams Obstetrics $22^{\text {nd }}$ edition; Section IV, chapter 18; 2005:447-457.

6. Low JA, Simpson LL, Tonni G, Chamberlain S. Limitations in the clinical prediction of intrapartum fetal hypoxia. Am J Obstet Gynecol. 1995;172:8014.

7. Goodlin RL, Haesslein HC. When it is fetal distress? Am J Obstet Gynecol. 1977;128:440-5.

8. Grant A, O' Brien N, Joy MT. Cerebral palsy among children born during the Dublin randomized trial of intrapartum monitoring. Lancet. 1989;2:1233-6.

9. Gourounti K, Sandall J. Admission Cardiotocography versus intermittent auscultation of 
fetal heart rate: effects on neonatal Apgar score, on the rate of cesarean section and on the rate of instrumental delivery. Int $J$ Nurs Stud. 2007;44(6):1029-40.

10. Impey L, Reynolds M, MacQuillan K, Gates S, Murphy J, Sheil O. Admission cardiotocography: a randomised controlled trial. The Lancet. 2003;361(9356):465-70.

11. Vintzileos AM, Antsaklis AR, Varvarigos IO, Papas CO, Sofatzis IO, Montgomery JT. A randomized trial of intrapartum fetal heart rate monitoring versus intermittent auscultation. Obstet Gynecol. 1993;81:899-907.

12. Zalar RW, Quilligan EJ. The influence of scalp sampling on the cesarean section rate for fetal distress. Am J Obstet Gynecol. 1979;135:239-46.

13. Steer PJ, Eigbe F, Lissaeur TJ, Beard RW. Interrelationship among abnormal cardiotocograms in labour, meconium staining of amniotic fluid, arterial cord blood $\mathrm{pH}$ and Apgar scores. Obstet Gyneco. 1989;74:715-21.

14. Palomaki O, Leukkaala T, Luoto R, Tuimala R. Intrapartum Cardiotocography the dilemma of interpretational variation. $\mathrm{J}$ Perinat Med. 2006;34(4):298-302.

15. Mahomed K, Nyomi R, Mulambo T, Kasula J, Jacobus E. Randomised controlled trial of intrapartum fetal heart rate monitoring. BMJ. 1994;308:497-500.

Cite this article as: Sen M, Samal S, Datta S, George M. Abnormal cardiotocographic findings and perinatal outcome: a prospective study. Int J Reprod Contracept Obstet Gynecol 2019;8:4261-70. 